\title{
A critical evaluation of promotional drug literatures available with prescribers at a tertiary care teaching hospital in Gujarat, India
}

\author{
Vimesh R. Mistry, Neeta J. Kanani, Kuntal S. Thacker*
}

Department of Pharmacology, Medical College Baroda, Vadodara, Gujarat, India

Received: 16 December 2021

Accepted: 13 January 2022

*Correspondence:

Dr. Kuntal S. Thacker,

Email: kuntalsiddhu@gmail.com

Copyright: ( ) the author(s), publisher and licensee Medip Academy. This is an open-access article distributed under the terms of the Creative Commons Attribution Non-Commercial License, which permits unrestricted non-commercial use, distribution, and reproduction in any medium, provided the original work is properly cited.

\begin{abstract}
Background: Promotional literature provided by the pharmaceutical companies is one of the important marketing strategies to prescribe. Many of these literatures do not follow ethical guidelines and contain biased and irrelevant information that may cause irrational prescribing. So we did this study with an aim to check the credibility, reliability and authenticity of the PDLs available with prescribers.

Methods: Promotional drug literatures were analyzed based on various parameters and guidelines provided by world health organization. Statistical analysis was done using Microsoft Excel.

Results: A total 395 promotional drug literatures were analyzed and very few of them fulfilled the ethical criteria for drug promotion. Most of them focused on providing information about generic name, brand name manufacture company name and claims about efficacy. Few of them focused on safety of drugs as less information provided about adverse reaction, precaution and drug-drug interaction. Many of them contain space occupying unnecessary pictures. Conclusions: It can be concluded that the majority of the promotional advertisements that were given to the prescribers do not follow ethical guidelines and were not able to improve rational prescribing but only have commercial benefits.
\end{abstract}

Keywords: Promotional drug literature, WHO criteria, ethical promotion

\section{INTRODUCTION}

According to WHO, 'drug promotion' refers to "all informational and persuasive activities by manufactures and distributors of the pharmaceutical industry, the effect of which is to induce a favourable prescription, supply, purchase and /or use of medicinal drugs". ${ }^{1,2}$ It includes activities of the medical representatives, drug advertisements and provision of gifts and free drug samples to prescribers, drug package inserts, direct-toconsumer advertisements, periodicals, telemarketing, holding of conferences, symposium, scientific meetings, sponsoring of medical education, visual aids, flip charts and conduct of promotional trials. ${ }^{3}$
Many studies conducted previously concluded that increased promotion is usually associated with increased sales. ${ }^{4}$ A major promotional technique used by pharmaceutical companies is direct-to-physician (DTP) marketing. ${ }^{5}$ The important sources of information for physicians on any new drug include textbooks, briefings by medical representatives, journal manuscripts, product monograms from pharmaceutical companies, drug promotional literature etc. Most health professionals get their information from commercial sources, usually through an extensive network of medical representatives to keep themselves updated with the ever changing scientific knowledge of medicines. ${ }^{6}$ Medical Representatives target prescribers through weekly or monthly visits, distributing samples, and attractive, eyecatching promotional drug literatures (PDL)s. PDLs 
includes product characteristics, side effects, dosage regime, contraindications and various marketing claims with references. The information provided in DPL should be authentic, unbiased and complete in order to enable prescriber to select and use the drug appropriately in a given patient. All promotion making claims concerning medicinal drugs should be reliable, accurate, truthful, informative, balanced, upto date, and capable of substantiation and in good taste. They should not contain any misleading or unverifiable statements or omissions likely to induce medically unjustifiable drug use or to give rise to undue risks. ${ }^{7}$ But the information and claims in PDLs sometimes misleading and inaccurate. ${ }^{8}$ So PDL provided by the pharmaceutical companies cannot be entirely relied upon for being disseminating drug information for their own interest, still they tends to have a powerful impact on physicians prescribing behavior. ${ }^{9,10}$ These promotional activities create the potential for inappropriate prescribing practices by influencing physicians' prescribing behavior without necessarily benefiting the patients but contributes to increased health care costs. ${ }^{11,12}$ There are ethical guidelines that need to be followed for the promotion of drugs at the national, as well as the international level. There are two important guidelines that are to be followed for the regulation of drug promotional activities at the international level; they are the ethical criteria for medicinal drug promotion by WHO and the code of pharmaceutical marketing practices by international federation of pharmaceutical manufacturers association (IFPMA). The majority of the drug promotional activities in India are governed by the organization of pharmaceutical producers of India (OPPI), which is a self-regulatory code of pharmaceutical marketing practices. ${ }^{13,14}$ The main objective of these ethical criteria for medicinal drug promotion is to support and encourage the improvement of health care through the rational use of medicinal drugs.

While many drug promotional ads provide no reference to scientific evidence in support of the claims made, those that do cite external documents might misrepresent the scientific data or report the data inaccurately. ${ }^{5}$ However, many studies have been presented that information provided through drug promotional activities is not consistent with the regulatory guidelines. ${ }^{15,16}$ This can affect the drug prescription, utilization, and sometimes can be irrational. So we plan this study with aims to check the credibility, reliability and authenticity of the PDLs among the prescribers, which are given to them by the medical representatives. With this background, the present study was conducted with the primary objectives of the evaluation of the drug promotional literature of different pharmaceutical companies on the basis of WHO guidelines on ethical drug promotion.

\section{METHODS}

This observational, cross-sectional study was conducted in the department of pharmacology, medical college and SSG hospital Vadodara, Gujarat from July 2019 to
December 2019. Approximately 467 leave behind brochures were collected from various outpatient departments like medicine, obstetrics and gynaecology, paediatrics, surgery, psychiatry, ophthalmology, orthopaedics and skin. Literature promoting Ayurveda medicines, drug monographs, medical devices and equipments, orthopedic prosthesis, reminder advertisements, drug promoting more than 2 brands and drugs name list was excluded from the study. All collected PDLs were analyzed according to WHO criterias for drug promotion. As per WHO criteria for ethical medicinal drug promotion, the promotional literature should contain following information; the name(s) of the active ingredient(s) using either international nonproprietary names (INN) or the approved generic name of the drug; the brand name; amount of active ingredient(s) per dose; other ingredients known to cause problems, i.e. adjuvant; approved therapeutic uses; dosage form or dosage schedule; safety information including side effects and major adverse drug reactions; precautions, contraindications and warnings; major drug interactions; name and address of manufacturer or distributor; reference to scientific literature as appropriate.

PDLs were evaluated for various claims about the product and claims were classified into seven categories as efficacy, safety, cost, convenience, pharmacokinetic property, pharmaceutical property and exaggerated emotional claims. PDLs were also evaluated for any catchy terms were used or not. References were also classified into journal, website, books, guidelines or others. Pictorial content of the promotional brochures was evaluated for the type of pictures (men, women, elderly, children, doctors, medicinal products, or other treatment unrelated pictures) and number of scientific Figures. A pretested and pre-validated checklist was prepared in which data was collected. All collected data were entered in Microsoft Excel and analyzed.

\section{RESULTS}

A total of 467 promotional drug literatures were collected from the outpatient department of medicine, surgery, obstetrics and gynecology, pediatrics, dental, orthopedics, ophthalmology and otorhinology of our hospital. Out of which 395 were included in our study for analysis and 72 (Ayurveda medicines, drug monographs, medical devices and equipments, orthopedic prosthesis, reminder advertisements, drug promoting more than 2 brands) were excluded as per exclusion criteria. Analysis of 395 PDLs were done for various parameters as mentioned below: single/fixed dose combinations (FDCs). Out of 395 PDLs, $164(42.52 \%)$ PDLs promoted single drug formulation and 231 (58.48\%) PDLs promoted fixed dose combinations of 2 or more drugs.

\section{System wise classification}

Out of 395 drugs, antimicrobials were most promoted group of drugs followed by agents affecting endocrine 
system, miscellaneous agents, cardiovascular agents, agents affecting central nervous system and agent acting on gastrointestinal system. Least promoting drugs include analgesic agents, agents affecting respiratory system and agents affecting blood (Figure 1).

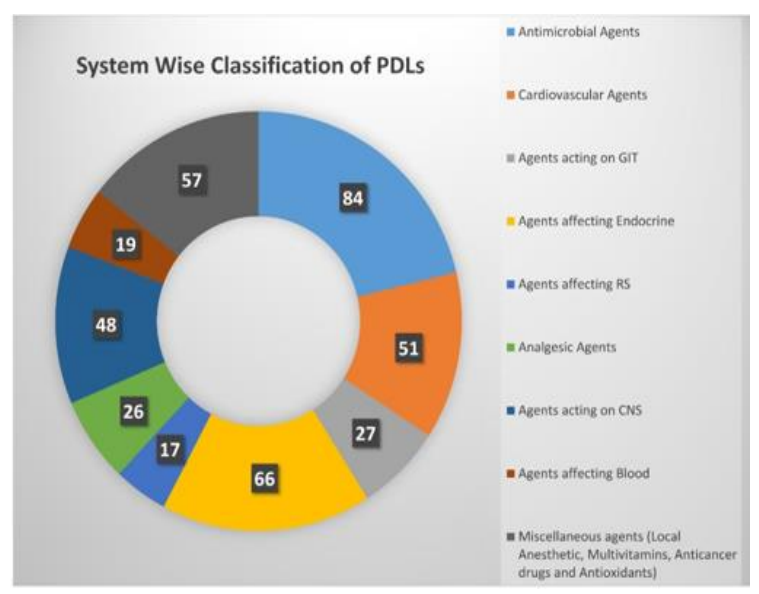

Figure 1: System wise classification of PDLs.

\section{WHO fulfillment criteria}

In our study, only 39 brochures fulfilled all criteria by WHO. Brand name was mentioned by all 395 brochures. Most of the brochures provided information regarding approved generic name, amount per dose, approved therapeutic use and references. Very few brochures provided information regarding adjuvants, dosage schedule, adverse drug reactions, precaution and drug interactions. Out of 395 brochures, information about name and address of manufacturer both were mentioned by 223 while only name of manufacturer was mentioned by 64 brochures (Table 1 ).

Table 1: Number of PDLs fulfilling WHO criteria $(n=395)$.

\begin{tabular}{|ll|}
\hline WHO criteria & N $(\%)$ \\
\hline Approved generic name & $354(89.62)$ \\
\hline Brand name & $395(100)$ \\
\hline Amount per dose & $310(78.48$ \\
\hline Adjuvants & $44(11.1)$ \\
\hline Approved therapeutic use & $329(83.29)$ \\
\hline Dosage for or schedule & $137(34.68)$ \\
\hline ADR information & $46(11.64)$ \\
\hline Precaution, C/I and warnings & $49(12.40)$ \\
\hline Major D/I & $39(9.80)$ \\
\hline Name \& address of manufacturer & 223 \\
\hline Reference & 341 \\
\hline
\end{tabular}

Average 5.74 WHO criteria were fulfilled by each PDL claims. Apart from providing therapeutic information, PDLs made multiple claims regarding the product. More than one claim were made in each PDL. No claims were found in 35 PDLs. Some PDLs contain as much as 6 claims (Figure 2). A total of 1493 claims were made in 395 PDLs evaluated. Average 3.78 claims were made for each PDL. Further analyses of claims were done and all claims were categorized according to their type (Table 2). Some PDLs has given references for given claims. Out of 395 PDLs, References were cited for given claim in 341 PDLs. From total 1493 claims, references to support claims were cited for 934 claims.

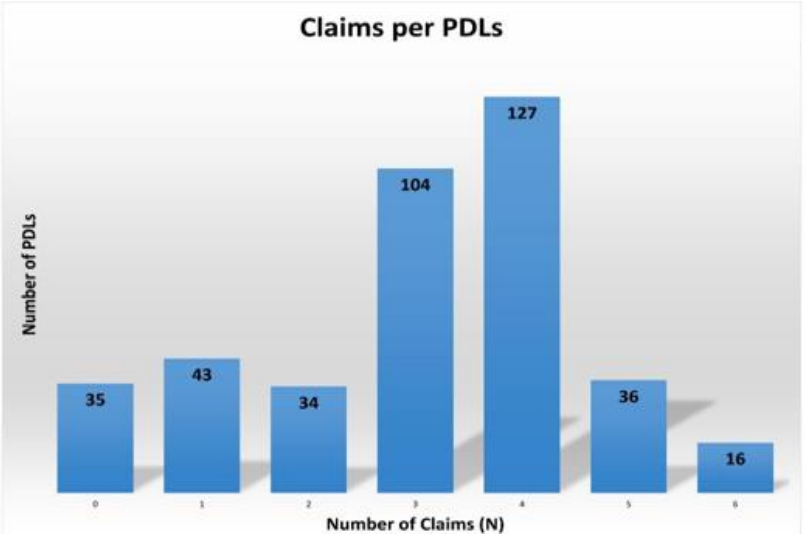

Figure 2: Number of claims per PDLs.

Table 2: Categorization of claims mentioned in PDLs.

\begin{tabular}{|ll|}
\hline Type of claims & Number \\
\hline Efficacy & 798 \\
\hline Safety & 314 \\
\hline Cost & 56 \\
\hline Convenience & 68 \\
\hline PK property & 60 \\
\hline Pharmaceutical property & 71 \\
\hline Exaggerated emotional claims & 126 \\
\hline No claim & 35 \\
\hline Total & 1493 \\
\hline
\end{tabular}

\section{References}

References were provided by PDLs to support various claims. Total 1148 references were found in 395 PDLs as some PDLs contain no references while some contain more than one references. Average 2.91 references were mentioned for each PDL. References were further classified according to their sources. Majority of references were of journal articles (Table 3).

\section{Catchy terms}

Various catchy terms were used by pharmaceutical industry to make PDLs more attractive. Out of 395 , catchy terms were used in 274 PDLs.

\section{Pictures}

These promotional literatures contain various pictures which contains majority of area of PDL. Analysis about 
pictures were done based on whether PDL contain picture or not and further classification of pictures were done based on their type. Out of 395, different type pictures contained by 346 PDLs. Some PDLs contain more than one picture. Total number of pictures counted was 636 . Most of the pictures in PDLs were regarding medicinal products (Table 4 ).

Table 3: Categorization of references mentioned in PDLs.

\begin{tabular}{|ll|}
\hline Sources of references & Number \\
\hline Journal & 672 \\
\hline Website & 143 \\
\hline Books & 45 \\
\hline Guidelines & 57 \\
\hline Other / Unclassified & 231 \\
\hline Total & 1148 \\
\hline
\end{tabular}

Table 4: Type of pictures in PDLs.

\begin{tabular}{|l|l|}
\hline Type of picture & Number \\
\hline Man & 12 \\
\hline Woman & 109 \\
\hline Elderly & 6 \\
\hline Children & 45 \\
\hline Doctors & 15 \\
\hline Medicinal products & 327 \\
\hline Unrelated & 122 \\
\hline No pictures & 49 \\
\hline Total & 636 \\
\hline
\end{tabular}

\section{Table and scientific figures}

Only few PDLs showed tables and various scientific figures. From total 395 PDLs analyzed, Tables were shown in 78 PDLs, scientific figures were shown in 63 PDLs and both were by only 8 PDLs.

\section{DISCUSSION}

In every year, hundreds of new drugs entering the market and most of them are "me too" drugs and not genuine innovations. Clinicians need to keep themselves well informed and updated about the new drugs. Different ways are used by pharmaceutical companies to promote their products and the amount spent on promotion of drugs approximates or perhaps even exceeds that spent on research and development. ${ }^{13}$ Among the different methods, one important way of the promotion of pharmaceutical product is Direct to physician (DTP) marketing. ${ }^{17}$ In Direct to physician (DTP) marketing, drug promotional literatures are commonly used as a promotional tool which contain information about the drug. The information provided for drug promotion should be accurate, scientific and evidence based to keep the physicians well informed. ${ }^{18}$ Most healthcare professionals rely on commercial sources of drug information from medical representatives and drug advertisement brochures and it has great impact on prescribing behavior. ${ }^{6}$ So the information provided in PDL should be in ethical manner and promotional claims need to be reliable, truthful, informative, balanced, and up to date. The drug promotional practices carried out by the pharmaceutical companies are more for a commercial purpose and not with aim to improve rational prescribing. Many ethical criteria are published for medicinal drug promotion by WHO and the code of pharmaceutical marketing practices by international federation of pharmaceutical manufacturers association across the globe and in india these are governed by the organization of pharmaceutical producers of India, a self-regulatory code of pharmaceutical marketing practices. While promoting their products, pharmaceutical industries should adhere to these ethical principles but it is not seen and it may cause irrational use of drugs. ${ }^{3} \mathrm{~A}$ similar trend is also seen in drug advertisements in medical journals published by many institutes and societies. ${ }^{19}$

Main objective of this study was to critically evaluate various PDLs according to WHO criteria and identify flaws in drug promotion. In our study of PDL analysis, PDLs promoting FDCs products were more in comparison to single drug formulations. Similar results were found in study done by Sekar et al. ${ }^{20}$ In some of the other studies PDLs promoting single drugs were more than FDCs. ${ }^{21-24}$ Reason for this may be because FDCs prices were higher than single drug formulations generally. ${ }^{25}$ Mostly companies want to promote products with more prices to earn more profit.

It was found in our study that cardiovascular agents, antidiabetic drugs and antimicrobials were among the top three groups of drugs being promoted, indicating that pharmaceutical companies were targeting chronic diseases which are widely prevalent. This finding was in concordance with a study conducted in Mumbai and other cities. ${ }^{20,21,24}$ Cardiovascular diseases and diabetes mellitus are chronic disease which requires lifelong treatment and various infections are also common among community. So because of these reasons promotion of these drugs were more.

On analysis of PDLs by WHO criteria, we found that most of the brochures provided information regarding approved generic name, amount per dose, approved therapeutic use and references. Similar findings were seen in other studies done in different cities also. ${ }^{25,26}$ Very few brochures provided information regarding adjuvants, dosage schedule, adverse drug reactions, precaution and drug interactions. These suggest that companies were least concerns with the safety of the drug and their main focus was on only showing good things about drugs. Similar concerns seen with previous studies done by Alam et al and others. This shows that these problem is not only region specific but it was wide spread in India. $^{27,28}$ In our study, various claims were provided about drugs' characteristics ranging from 0-6 claims each 
PDL. These claims sometimes may be misleading as they were not provided with references and sometimes references were not retrievable. Majority of claim was about efficacy. Similar claims were found in other studies by Stimson and Randhava et al. ${ }^{29}$ In our study, most of PDLs contain references while some were without references. Among categorization of references, more than $50 \%$ references were of journal articles. Though references were given but their quality and authenticity should be checked before accepting that references. Similar results about references were seen with studies done by Jadav et al and Khakhkhar et al and others. ${ }^{18,31,32}$

Various catchy terms were used in more than $70 \%$ PDLs to look them attractive. Some of these catchy terms were irrelevant to the products. A study done by Vyas has also found around $75 \%$ PDLs with catchy terms. ${ }^{33}$ Among the analysed PDLs, around $80 \%$ of PDLs contains various pictures. Categorizations of these pictures were done and $50 \%$ of pictures were of the medicinal products and others were that of women and some of them were not related to products. Same results were seen in study done by Ganashree et al. These pictures covers more space in brochure so rather than showing picture these space can be utilized for providing more information about the drugs that can be useful for prescribers. ${ }^{34}$ Data presented in scientific figures and tables is seen in very few PDLs. Supportive data such as diagrams can help to demonstrate the level of significance with regards to parameters studied and also help the prescriber select an appropriate drug. Inclusion tables and scientific figures is recommended to improve the scientific validity of PDLs.

We need to encourage our doctors to acquire skill to do critical appraisal of PDLs possibly during their undergraduate training. This would compel them to look up to the authentic medical literature for reference and to be cautious not to rely solely on these PDLs. As most of the companies are interested in highlighting only positive aspects and ignoring negative aspects which may promote irrational prescribing and harm the consumers economically and health wise. It is a responsibility of a practicing physician to critically evaluate the information given in a drug promotional literature before taking it as a scientific source of information, and any flaws, if identified, should be reported to appropriate authority.

To improve the knowledge and awareness regarding information about ethical drug promotion, undergraduate's students should be given various interventional educational research, workshops and training programs. To verification of awareness levels of the physicians aboutethical drug promotion should be done by various interventional research and appropriate measures should be taken to improve their skills to acquire right information. ${ }^{21}$ Some of the important measures to improve these issues are improve awareness in prescribers, strict implementation of existing laws and development of guidelines and their implementation by pharmaceutical companies for drug promotion. Combined efforts of physicians, pharmaceutical industries, and regulatory authority can help in ethical promotion of a drug and rational prescribing which mainly benefit the patients and society which truly serve the purpose of "health for all".

\section{CONCLUSION}

From our study, it can be concluded that the majority of the promotional advertisements that were given to the prescribers do not follow ethical guidelines and were not able to improve rational prescribing but only have commercial benefits. Therefore, it is responsibility of the physicians to critically analyze these PDLs before using them as a valid source of drug information. Ethical drug promotion and rational prescribing can only be achieved by combined efforts of physicians, pharmaceutical industry.

\section{ACKNOWLEDGEMENTS}

Authors are thankful to the various clinical departments of the hospital for their cooperation and support.

Funding: No funding sources

Conflict of interest: None declared

Ethical approval: The study was approved by the Institutional Ethics Committee

\section{REFERENCES}

1. Ethical criteria for medicinal drug promotion. Available at: http://apps.who.int/medicinedocs/ documents/whozip08e/whozip08e.pdf. Assessed on 10 May 2019.

2. Sahne BJ, Yegenoglu S, Uner M, Wertheimer AI. Adherence of drug advertisements to the international marketing codes. Hacettepe Uni J Faculty Pharmacy. 2012;32(1):53-6.

3. Lal A. Pharmaceutical drug promotion: how it is being practiced in India? J Assoc Physicians India. 2001;49:266-73.

4. Drug Promotion: Reviews of Materials in the WHO/HAI Database on Drug Promotion. Available at: http://www.drugpromo.info. Assessed on 10 May 2020.

5. Cooper RJ, Schriger DL. The availability of references and the sponsorship of original research cited in pharmaceutical advertisements. CMAJ. 2005;172:487-91.

6. Gopalakrishnan S, Murali R. India: Campaign to tackle unethical promotion. Available at: http://www.apps.who.int/medicinedocs/pdf/s4937e/s 4937e.pdf. Assessed on 10 May 2020.

7. Ethical criteria for medicinal drug promotion. Available at: http://apps.who.int/medicinedocs/ documents/whozip08e/whozip08e.pdf . Assessed on 10 May 2020.

8. Rohra DK, Gilani AH, Memon IK, Perven G, Khan MT, Zafar H, et al. Critical evaluation of claims 
made by pharmaceutical companies in drug promotional material in Pakistan. J Pharm Pharm Sci. 2006;9:50-9.

9. Chitnis K, Limaye A, Bhosale M. Pharmaceutical promotional literature: Opinions of physicians in a tertiary care hospital in Mumbai. Int $\mathbf{J}$ Basic Clin Pharmacol. 2013;2:541-7.

10. Cardarelli R, Licciardone JC, Taylor LG. A crosssectional evidence based review of pharmaceutical promotional marketing brochures and their underling studies: Is what they tell us important and true? BMC Fam Pract. 2006;7:13.

11. Brody H. The company we keep: Why physicians should refuse to see pharmaceutical representatives. Ann Fam Med. 2005;3:82-5.

12. Wazana A. Physicians and the pharmaceutical industry: Is a gift ever just a gift?. JAMA. 2000;283: 373-80.

13. International Federation of Pharmaceutical Manufacturers and Associations (IFPMA). Available at: http://www.ifpma.org. Assessed on 10 May 2020.

14. OPPI code of pharmaceutical marketing practices. Available at: http://www.indiaoppi.com/OPPI\%20 Code\%20of\%20Marketing\%202007.pdf. Assessed on 10 May 2020.

15. Smart S, Williams C. Evidence based advertising? Half of drug advertisements in BMJ over six months cited no supporting evidence. BMJ. 1997;315:16223.

16. Mindell J, Kemp T. Evidence based advertising? Only two fifth of advertisements cited published, peer reviewed references. BMJ. 1997;315:1622.

17. Villanueva P, Peiro S, Librero J, Pereiro I. Accuracy of pharmaceutical advertisements in medical journals. Lancet. 2003;361:27-32.

18. Khakhkhar T, Mehta M, Shah R, Sharma D. Evaluation of drug promotional literatures using WHO guidelines. J Pharm Negative Results. 2013; 4:33-8.

19. Nath S, Bhowmick S, Dutta T, Chowrasia VR, Bhattacharya S, Chatterjee RN, et al. A study of promotional advertisements of drugs in a medical journal: An ethics perspective. Indian J Med Ethics. 2014;11:237-41.

20. Sekar P, Punnagai K. Evaluation Of The Rationality Of Claims Made In Drug Promotional Literature In West Chennai. Asian J Pharm Clin Res. 2015;8(5): 107-9.

21. Mali SN, Dudhgaonkar S, Bachewar NP. Evaluation of rationality of promotional drug literature using World Health Organization guidelines. Indian J Pharmacol. 2010:42(5);267-72.

22. Rani SG, Chugh PK, Sah RK, Tripathi CD. Critical appraisal of drug promotional literature using World Health Organisation guidelines. Int $\mathrm{J}$ Basic Clin Pharmacol. 2017;6:2014-9.
23. Hao J, Rodriguez-Monguio R, Seoane-Vazquez E. Fixed-dose combination drug approvals, patents and market exclusivities compared to single active ingredient pharmaceuticals. PLoS One. 2015;10(10) :e0140708.

24. Shetty VV, Karve AV. Promotional literature: How do we critically appraise? J Postgrad Med. 2008; 54:217-21.

25. Garje YA, Ghodke BV, Lalan HN, Senpaty S, Kumar R, Solunke S. Assessment of Promotional Drug Literature Using World Health organisation (WHO) Guidelines. Indian J App Res. 2014;4(2): 2249-351.

26. Jain VK, Kaore SN, Amane HS, Jain M, Katakwar M, Thawani V. Evaluation of rationality of printed promotional medicine literature. Int $\mathbf{J}$ Health Allied Sci. 2016;5:45-9.

27. Alam K, Shah AK, Ojha P, Palaian S, Shankar PR. Evaluation of drug promotional materials in a hospital setting in Nepal. Southern Med Rev. 2009; 2(1):2-6.

28. Sonwane PG, Karve AV. Drug promotional literature: Does pharmaceutical industry follow WHO guidelines?. Int J Basic Clin Pharmacol. 2017; 6:1790-3.

29. Stimson GV. Information contained in drug advertisements. Br Med J 1975;4:508-9.

30. Randhawa GK, Singh NR, Rai J, Kaur G, Kashyap R. A critical analysis of claims and their authenticity in Indian drug promotional advertisements. Adv Med. 2015:46:9147.

31. Jadav SS, Dumatar CB, Dikshit RK. Drug promotional literatures (DPLs) evaluation as per World Health Organization (WHO) criteria. J App Pharm Sci. 2014;4(6):84-8.

32. Chaudhari A, Zaveri J. A study on critical review of drug promotional literature using the WHO Guidelines. Int J Sci Stud. 2019;7(2):1-4.

33. Vyas DJ. A critical evaluation of drug promotional literatures provided to prescribers at a tertiary care teaching hospital in Gujarat. Sch J App Med Sci. 2017;5(10F):4239-43.

34. Ganashree P, Bhuvana K, Sarala N. Critical review of drug promotional literature using the World Health Organization guidelines. J Res Pharm Practice. 2016;5(3):162-5.

Cite this article as: Mistry VR, Kanani NJ, Thacker KS. A critical evaluation of promotional drug literatures available with prescribers at a tertiary care teaching hospital in Gujarat, India. Int J Basic Clin Pharmacol 2022;11:167-72. 